\title{
Death Anxiety ditinjau dari Meaning in life pada Lanjut Usia di Panti Jompo Taman Bodhi Asri (TABA) Medan
}

\section{Anxiety about the meaning of death in the meaning of the life of the Elderly at the Taman Bodhi Asri Nursing Home (TABA) Medan}

\author{
Mikha Rizki Siahaan \\ Fakultas Psikologi, Universitas Prima Indonesia, Indonesia
}

Diterima : 12 Agustus 2020; Disetujui : 24 Agustus 2020; Dipublish : 29 Agustus 2020

*Corresponding author: E-mail: mikhasiahaan79@gmail.com

\begin{abstract}
Abstrak
Penelitian ini bertujuan untuk mengetahui hubungan antara death anxiety dengan meaning in life. Hipotesis yang diajukan dalam penelitian ini adalah ada hubungan negatif antara death anxiety dengan meaning in life, dengan asumsi semakin tinggi death anxiety, maka semakin tinggi meaning in life dan sebaliknya semakin rendah death anxiety maka semakin rendah meaning in life. Subjek penelitian yang digunakan dalam penelitian ini adalah lanjut usia di panti jompo Taman Bodhi Asri (TABA) Medan sebanyak 80 orang. Data diperoleh dari skala untuk mengukur death anxiety dan meaning in life. Perhitungan dilakukan dengan melakukan uji prasyarat analisis uji (uji asumsi) yang terdiri dari uji normalitas dan uji linieritas. Analisis data yang digunakan adalah menggunakan korelasi Product Moment melalui bantuan SPSS 17 for windows. Hasil analisis data menunjukkan koefisien korelasi sebesar -0.552 dan nilai signifikansi sebesar $0.000(\mathrm{p}<0.05)$ ini menunjukkan ada hubungan negatif antara death anxiety dengan meaning in life. Hasil penelitian ini menunjukkan bahwa sumbangan yang diberikan variabel death anxiety terhadap meaning in life sebesar 30,5 persen, selebihnya 69,5 persen dipengaruhi oleh faktor lain yang tidak diteliti. Jadi, dapat ditarik kesimpulan bahwa hipotesis penelitian, yaitu ada hubungan negatif antara death anxiety dengan meaning in life dapat diterima.
\end{abstract}

Kata Kunci : Death Anxiety; Meaning in Life.

\begin{abstract}
This study aims to determine the correlation between death anxiety with meaning in life in the elderly. The hypothesis proposed in this study is that there is a negative relationship between death anxiety between meaning in life in the elderly, assuming the higher death anxiety, the lower the meaning in life, and conversely the lower the death anxiety, the higher the meaning in life. The research subjects in this study were 80 elderly people in nursing homes in Bodhi Asri Park (TABA) Medan who were selected by the total sampling method. Data is obtained from a scale that measures death anxiety and meaning in life. The calculation is done through analysis prerequisite test (assumption test) which consists of normality test and linearity test relationship analysis of the data used is using product moment correlation through the help of SPSS 17 for windows. The results of data analysis showed a correlation coefficient of -0.552 with $p$ of 0.000 ( $p$ $<0.05)$. This shows that there is a negative relationship between deant anxiety and meaning in life in the elderly. The results of this study indicate that the contribution of death anxiety variables to 30.5 percent of death anxiety affects the meaning in life of elderly Bodhi Asri Park foundations, while 69.5 percent is influenced by other factors such as religiosity, subjective well being, psychological meaning, life well-being. Based on this study, the hypothesis is acceptable, namely there is a negative relationship between death anxiety towards meaning in life.
\end{abstract}

Keywords: Death Anxiety; Meaning in Life.

Rekomendasi mensitasi :

Siahaan, M.R. 2020, Death Anxiety ditinjau dari Meaning in life pada Lanjut Usia di Panti Jompo Taman Bodhi Asri (TABA) Medan. Jurnal Penelitian Pendidikan, Psikologi dan Kesehatan (J-P3K), 1 (2) : 157-162. 


\section{PENDAHULUAN}

Manusia sebagai makhluk hidup yang sempurna, hal ini dikarenakan manusia memiliki akal yang membedakan dirinya dengan makhluk lainya. Kehidupan adalah sebuah kesempatan yang sangat berharga untuk kita. Perkembangan yang terjadi dalam kehidupan manusia diawali oleh kelahiran, balita, anak-anak, remaja, dewasa, dan lanjut usia. Sebagian besar manusia memiliki tujuan hidup dan arti kehidupan masing-masing. Setiap menjalani kehidupan setiap orang akan memberikan makna kepada setiap yang ia lakukan dan setiap orang akan lebih memperhatikan yang ia lakukan tersebut sesuai dengan nila-nilai agama yang ia anut.

Usia tua adalah periode penutup dalam rentang hidup seseorang, yaitu suatu periode dimana seseorang telah beranjak jauh dari periode terdahulu yang lebih menyenangkan atau beranjak dari waktu yang penuh dengan manfaat. Masa tua ditandai oleh adanya perubahan jasmani dan perubahan mental (Jahja, 2015).

Pada orang lanjut usia biasanya memiliki kecenderungan penyakit kronis dan progresif sampai penderitanya mengalami kematian. Proses penuaan dibarengi bersamaan dengan menurunnya daya tahan tubuh serta metabolisme sehingga menjadi rawan terhadap penyakit, tetapi banyak penyakit yang menyertai proses ketuaan dewasa ini dapat dikontrol dan diobati (Nugroho, 2006).

Menurut Santrock

(2002) mengatakan orang dewasa lanjut usia pemikirannya dan pembicaraan mengenai kematian meningkat, perkembangan integritas pun meningkat melalui peninjauan hidup yang positif dan hal ini mungkin dapat membantu mereka untuk menerima kematian. Orang dewasa lanjut usia sudah dapat menerima kematian itu lebih baik karena mereka merasa bahwa mereka telah melakukan apa yang mereka ingin lakukan dan bermanfaat buat sekelilingnya. Berbanding terbalik dengan orang dewasa muda ketika diperhadapkan dengan kematian, mereka akan merasa bahwa hidupnya sia-sia sedangkan orang dewasa menengah menganggap bahwa kematian telah mengambil semua yang telah diperoleh. Kurangnya antisipasi terhadap kematian barangkali akan menyebabkan rendahnya rasa sakit yang ditimbulkan secara emosional pada diri mereka.

Penney (2012), mengatakan kematian adalah bagian normal dalam kehidupan, namun dapat beresiko tinggi jika tidak ada dukungan yang tersedia. Sedangkan menurut Penney kematian adalah sesuatu yang sudah jelas-jelas diketahui, dan dapat dipastikan kejadiannya. Sebab itu takut mati adalah bagian dari lapisan kesadaran pertama, lapisan fisik. Kematian merupakan kepastian, maka secara psikologis pengaruhnya amat besar dalam bawah sadar kehidupan seseorang dan dalam perilaku manusia.

Menurut kamus psikologi Chaplin Kecemasan atau anxiety adalah perasaan takut bercampur tidak bahagia tentang masa depan tanpa alasan tertentu bagi ketakutan itu. Kecemasan yang menyebabkan seseorang putus asa dan tidak berdaya sehingga mempengaruhi seluruh kepribadiannya adalah 
kecemasan yang negatif. Rasa takut ditimbulkan oleh adanya ancaman, sehingga seseorang akan menghindari diri dan sebagainya. Kecemasan dapat ditimbulkan oleh bahaya dari luar, mungkin juga oleh bahaya dari dalam diri seseorang, pada umumnya ancaman itu samar-samar. Bahaya dari dalam, timbul bila ada sesuatu hal yang tidak dapat diterima nya, misalnya pikiran, perasaan keinginan, dan dorongan.

Menurut Bastaman (2007) meaning in life adalah hal-hal yang dianggap sangat penting dan berharga serta memberikan nilai khusus bagi seseorang, sehingga layak dijadikan tujuan dalam kehidupan.

Menurut Kastenbaum dan Costa (dalam Bryant, 2003), death anxiety merupakan salah satu respons terhadap pertanyaan tentang makna kematian, dan kecemasan semacam itu sebenarnya bisa menjadi gabungan respons yang kompleks. Sedangkan Williams (2009), mengatakan seseorang yang takut akan kematian bahwa kematian identik dengan kepunahaan atau pemusnahan diri, dengan kata lain begitu kita mati kita sudah tidak ada lagi atau kita pergi untuk selamanya.

Terdapat penelitian terdahulu yang dilakukan oleh Golzar dan Toozandehjani (2015) menunjukkan bahwa kecemasan kematian (death anxiety) dipengaruhi oleh makna hidup (meaning in life), Hasil dari penelitian ini menunjukkan adanya hubungan yang negatif dan signifikan antara makna hidup dengan kecemasan kematian.

Berdasarkan uraian di atas, dapat disimpulkan bahwa adanya hubungan yang negatif antara death anxiety dengan meaning in life pada lanjut usia. Semakin tinggi meaning in life, maka death anxiety pada lansia rendah, atau sebaliknya semakin rendah meaning in life, maka death anxiety pada lanjut usia semakin tinggi.

\section{METODE PENELITIAN}

Populasi dalam penelitian ini adalah semua usia lanjut yang berada di Yayasan Taman Bodhi Asri Medan. Metode pengambilan sampel pada penelitian ini menggunakan metode total sampling dengan karakteristik:

1. Wanita dan pria

2. Berusia di atas 60 tahun

Sehingga jumlah sampel pada penelitian ini adalah sebanyak 80 usia lanjut yang berada di Yayasan Taman Bodhi Asri Medan.

Metode pengumpulan data yang digunakan dalam penelitian ini adalah dengan pembagian skala, yaitu untuk skala Death Anxiety dan skala Meaning in Life. Jenis skala yang digunakan adalah skala Likert. Skala Death Anxiety disusun oleh peneliti berdasarkan dimensidimensi Death Anxiety yang dikemukakan oleh Cai, W, dkk., (2017), yaitu dysphoria (keresahaan yang tidak wajar), death intrusion (gangguan kematian), fear of death (ketakutan kematian), avoidance (penghindaran pada kematian). Skala meaning in life disusun peneliti berdasarkan dimensi-dimensi meaning in life yang dikemukakan oleh Tang, dkk., (2015), yaitu freedom of life, will to meaning, meaning of life.

Metode analisis data menggunakan korelasi Product Moment (Pearson Correlation) dengan bantuan SPSS 17 for windows untuk mengetahui bagaimana 
hubungan antara variabel death anxiety dengan variabel meaning in life.

\section{HASIL DAN PEMBAHASAN}

Sebelum dilakukan analisis Product Moment (Pearson Correlation), data yang terkumpul terlebih dahulu ditentukan normalitas sebaran dan linieritas hubungannya. Dari uji normalitas dan uji linieritas diketahui bahwa hasilnya memenuhi asumsi tersebut. Hasil uji normalitas sebaran dan uji linieritas hubungan dapat dilihat pada Tabel 1 dan Tabel 2 yaitu sebagai berikut.

Tabel 1. Hasil Uji Normalitas

\begin{tabular}{llllll}
\hline Variabel & SD & K-SZ & Sig. & P & Ket. \\
\hline Death & 6,8 & \multirow{2}{*}{0,994} & 0,1 & $\mathrm{P}>$ & Sebaran \\
Anxiety & 02 & & 38 & 0,05 & normal \\
Meaning & & & & & \\
in Life & 7,8 & 0,817 & 0,2 & $\mathrm{P}>$ & Sebaran \\
& 50 & & 58 & 0,05 & normal
\end{tabular}

Tabel 2. Hasil Uji Linieritas Hubungan

\begin{tabular}{lllll}
\hline Variabel & $\mathrm{F}$ & Sig. & $\mathrm{P}$ & Ket. \\
\hline $\begin{array}{l}\text { Death } \\
\text { anxiety* }\end{array}$ & & & & \\
$\begin{array}{l}\text { Meaning } \\
\text { in life }\end{array}$ & 45,442 & 0,000 & $\mathrm{P}<0,05$ & Linier \\
& & & & \\
\hline
\end{tabular}

Hipotesis dalam penelitian ini adalah hubungan negatif antara death anxiety dengan meaning in life pada usia lanjut yang berada di Yayasan Taman Bodhi Asri Medan. Hasil uji hipotesis dapat dilihat pada Tabel 3 yaitu sebagai berikut.

Tabel 3.Korelasi Antara meaning in life dengan death anxiety

\begin{tabular}{lll}
\hline Variabel & $\begin{array}{l}\text { Pearson } \\
\text { Correlation }\end{array}$ & Sig. \\
\hline $\begin{array}{l}\text { Meaning in } \\
\text { life*Death anxiety }\end{array}$ & $-0,552$ & 0,000 \\
\hline
\end{tabular}

Berdasarkan hasil analisis korelasi antara kecerdasan spiritual dengan kebahagiaan, diperoleh koefisien korelasi Product Moment sebesar -0,552 dengan nilai p sebesar $0.000(\mathrm{p}<0.05$, Sig. 1 tailed). Hal ini menunjukkan adanya korelasi negatif antara death anxiety dengan meaning in life.

Tabel 4. Model Summary Sumbangan Efektif Sumbangan Efektif

\begin{tabular}{cllll}
\hline Model & $\mathrm{R}$ & $\begin{array}{l}R \\
\text { Square }\end{array}$ & $\begin{array}{l}\text { Adjusted } \\
\text { R Square }\end{array}$ & $\begin{array}{l}\text { Std. Error } \\
\text { of the } \\
\text { Estimate }\end{array}$ \\
\hline 1 & 0,664 & 0,441 & 0,438 & 9,513 \\
\hline
\end{tabular}

Berdasarkan Tabel 4, dapat disimpulkan sumbangan efektif yang dapat dilihat dari tabel $R$ square sebesar 0.305. Berdasarkan hasil tersebut, dapat disimpulkan bahwa 30,5 persen death anxiety mempengaruhi meaning in life dan selebihnya 69,5 persen dipengaruhi oleh faktor lain yang tidak diteliti, seperti religiusitas, subjective well being, kebermaknaan hidup, psychological wellbeing.

Adapun hasil penelitian ini juga sejalan dengan penelitian yang dilakukan oleh Babanzari, dkk., (2012). Hasil penelitian tersebut menyatakan bahwa terdapat hubungan yang positif antara kecerdasan spiritual dengan kebahagiaan, dengan sampel sebanyak 221 murid sekolah menengah atas Shiraz. Semakin tinggi kebahagiaan seseorang, maka semakin tinggi kecerdasan spiritual seseorang dan sebaliknya semakin rendah kebahagiaan seseorang, maka semakin rendah kecerdasan spiritual seseorang. 


\section{SIMPULAN}

Berdasarkan hasil-hasil yang telah diperoleh dalam penelitian ini, maka dapat disimpulkan sebagai berikut:

1. Ada hubungan negatif antara death anxiety dengan meaning in life pada lanjut usia di Panti Jompo Taman Bodhi Asri (TABA) dengan korelasi Product Moment (r) sebesar -0.552 dengan $\mathrm{p}$ sebesar 0,000 ( $\mathrm{p}<0,05)$, artinya semakin tinggi death anxiety yang dirasakan seseorang, maka meaning in life yang dimiliki akan semakin rendah, dan sebaliknya jika semakin rendah death anxiety yang dirasakan seseorang, maka meaning in life akan semakin tinggi.

2. Mean dari meaning in life pada subjek penelitian lanjut usia di Panti Jompo Taman Bodhi Asri (TABA) secara keseluruhan menunjukkan bahwa meaning in life subjek penelitian lebih besar dari pada populasi pada umumnya. Hal ini dapat dilihat dari nilai mean empirik sebesar 63,44 lebih besar dari mean hipotetik yaitu 57,5. Berdasarkan kategori, maka dapat dilihat bahwa terdapat lansia yang memiliki tingkat meaning in life yang rendah sebanyak 0 orang atau 0 persen, sedangkan yang memiliki meaning in life sedang 58 orang atau 72,5 persen, dan yang memiliki meaning in life tinggi sebanyak 22 orang atau 27,5 persen.

3. Mean dari death anxiety pada subjek penelitian lansia di Panti Jompo Taman Bodhi Asri (TABA) secara keseluruhan menunjukkan bahwa death anxiety subjek penelitian lebih besar daripada populasi pada umumnya. Hal ini dapat dilihat dari nilai mean empirik sebesar 63,96 lebih besar dari mean hipotetik yaitu 55. Berdasarkan kategori, maka dapat dilihat bahwa terdapat lansia yang memiliki tingkat death anxiety yang rendah sebanyak 0 orang atau 0 persen, sedangkan yang memiliki death anxiety sedang sebanyak 44 orang atau 55 persen, dan yang memiliki death anxiety tinggi sebanyak 36 orang atau 45 persen.

4. Hasil penelitian ini menunjukkan bahwa sumbangan yang diberikan variabel death anxiety terhadap meaning in life adalah sebesar 30,5 persen, selebihnya 69,5 persen dipengaruhi oleh faktor lain seperti religiusitas, subjective well being, kebermaknaan hidup, psychological well-being.

\section{DAFTAR PUSTAKA}

Bryant, D.C. 2003. Handbook of Death \& Dying (volume 2). Amerika: Sage Publications

Chaplin J. P. 2006. Kamus Lengkap Psikologi. Jakarta: PT.Raja Grafindo Persada.

Golzar, H \& Toozandehjani, H. 2015. Relationship Between Moral Intelligence and Meaning of life with Death Anxiety In Rescue Personal OF Sari City. Journal of Fundamental and Applied Available Life Sciences Voleme 5 dari

http://www.cibtech.org/sp.ed/jls/2015/o1/41 9-JLS-S1-421-HASAN-RELATIONSHIPCITY.pdf

Jahja, Y. 2015. Psikologi Perkembangan. Jakarta: Kencana

Hurlock, E.B. 1980. Psikologi Perkembangan :Suatu Pendekatan Sepanjang Rentang Kehidupan Edisi Kelima. Jakarta :Erlangga

Lopez, J. S. 2009. The Eacylopedia of PositifPscyhology. United States:WileyBlackwell

Lubis, R. 2017. Agama dan Perdamaian: Landasan, Tujuan, dan Realitas Kehidupan Beragama di Indonesia. PT Gramedia: Jakarta

Penney, U. 2012. Psikologi Perkembangan. Jakarta: Erlangga 
Nugroho, W. H. 2006. Komunikasi dalam Keperawatan Gerontik. Jakarta: Buku Kedokteran

Maryam, S., Ekasari, M., Rosidawati., Jubaedi, A.,\& Batubara, I. (2008). Mengenal Usia Lanjut dan Perawatanya . Jakarta: Salemba Medika

Priyatno D. 2010. Teknik Mudah dan Cepat Melakukan Analisis Data Penelitian dengan SPSS dan Tanya Jawab Ujian Pendadaran.Yogyakarta: Gava Media

Reker, T.G \& Chamberlain, K. 200o. Exploring Existensial Meaning: Optiizing Human Development Across the Life Span. Calivornia: Sage Publications, Inc

Renold, S. 2010. Beyond Borders: Communication Modernity \& History. London School : STIKOM The London School of Public Relations

Riris, S \& Nuryati, A. 2011. Self Esteem dan Makna Hidup pada Pensiun Pegawai Negeri Sipil (PNS).Yogyakarta: Universitas Gadjah Mada. Jurnal Psikologi Volume 38 No 2 hal 176-184 Diakses pada tanggal 30 maret 2016 dari https://goo.gl/a2xjvw

Soewadji, J. 2012. Life Span Development: Perkembanga Masa Hidup. Jakarta: Erlangga

Siti \& Fitri. 2014. Hubungan antara Religiusitas dengan Kecemasan kematian pada dewasa tengah. Jurnal Psikologi Kepribadiandan social Volume 03 No o1 dari http://journal.unair.ac.id/downloadfullpapers jpksd88e11899cfull.pdf

Suiraoka, IP. 2012. Penyakit Degeneratif: Mengenal, Mencegah, dan Mengurangi Faktor Resiko 9 Penyakit Degeneratif. Yogyakarta: Numes

Santrock, J. 2002. Life Span Development: Perkembangan Masa Hidup. Jakarta: Penerbit Erlangga

William, N. 2009. Conquer the fear of death. New Delhi: Epitome Books 